\title{
MEASURING OF OXYGEN MASS-TRANSFER THROUGH THE GAS-LIQUID INTERFACE
}

\author{
Erik Mölder \\ Aleksei Mashirin \\ Toomas Tenno \\ University of Tartu, Estonia
}

\begin{abstract}
In the present study, oxygen mass-transfer processes through the liquid-air interface from gas mixture with variable volume at constant pressure were investigated. This paper describes a device based on the electrochemical oxygen sensor placed on the liquid-air surface. The oxygen sensor measured the decrease of oxygen concentration in the small volume under the device, that is in contact with deoxygenated liquid. Experimental data obtained by the device were introduced to a novel mathematical model, which allowed calculating diffusion flow through the liquid-air interface and diffusional conductivity $\mathrm{P} / \mathrm{l}$ of liquid surface.
\end{abstract}

By means of the developed device it is possible to measure the total impediment of the air-water interface to oxygen mass-transfer.

\section{KEYWORDS}

Liquid-gas interface; oxygen mass-transfer; overall transfer velocity.

\section{INTRODUCTION}

Gas exchange through the air-water interface is one of the most important processes both in natural and sewage waters [1]. The ransport of oxygen as a biologically essential gas between water and the gas phase has a special importance. In natural waters the oxygen sources are dissolution of the oxygen from the air and the photosynthesis of plants.

In biological wastewater treatment one step is the activated sludge process where microbes are suspended into the water phase. As those microbes need oxygen to survive, there is a need to pump air or even oxygenenriched air into the aeration tank in order to increase the effectiveness of treatment. The activated sludge obtains oxygen for living and for the degradation of pollutants mainly from transfer through the gas-water interface of gas bubbles generated by the aeration system. The dissolution of oxygen in water depends on various factors such as temperature, $\mathrm{pH}$, stirring, etc. A substantial factor 
KALMAR ECO-TECH'03

Bioremediation and Leachate Treatment

KALMAR, SWEDEN, November 25-27, 2003

limiting oxygen diffusion into the water phase may be thin oil film and/or a layer of surfactants adsorbed on the water surface [2,3].

Consequently, if there are surfactants on the water surface there is a need to pump more oxygen into the aerotank in order to achieve the necessary oxygen concentration in the water phase. Additional air pumping consumes more energy and thus increases the operational costs of the treatment plant.

Investigation of the surfaces of natural water and sewage water is complicated because there are always multitudes of different surfactants on the air-water interface. Properties of the interfaces depend both on the amount of surfactants and interactions between them $[4,5,6]$.

\section{EXPERIMENTAL}

A special measurement cell was constructed for oxygen mass-transfer rate measurements [7]. The most important part of the measurement cell is a chamber containing the electrochemical oxygen sensor inside it (Figure 1). The oxygen sensor TriOximatic 300 and oxygen meter Oxi 3000 (Wissenschaftlich-Tehnische Werkstätten $\mathrm{GmbH}$ ) were used.

The measurement cell is placed into the sample solution. In order to create oxygen flow through the air-water interface, oxygen is eliminated from all solutions by adding $\mathrm{Na}_{2} \mathrm{SO}_{3}$. As the concentration of oxygen in the solution is zero, oxygen diffusion from the air to the solution takes place and oxygen concentration starts to decrease in the chamber.

All measurements were performed at $25^{\circ} \mathrm{C}$.

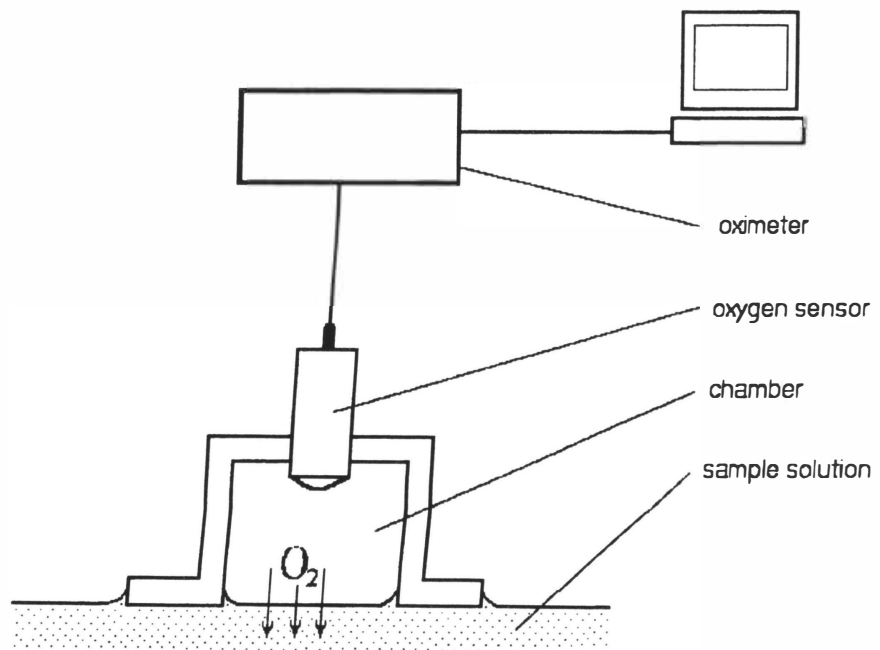

Figure 1. Scheme of the device. 
KALMAR ECO-TECH'03

Bioremediation and Leachate Treatment

KALMAR, SWEDEN, November 25-27, 2003

\section{RESULTS AND DISCUSSION}

The surfactants used in the test study were methanol, ethanol, 1-propanol, 1-butanol, and 1-penthanol. Oxygen mass-transfer rates for every solution investigated were compared with that for pure water.

Decrease of oxygen concentration in the cell during time was measured at different surfactant concentrations. By using this date was calculated the rate of the diffusion of oxygen across the air-water interface.

Based on the fact that at the beginning of the experiment oxygen concentration inside the cell is equal to oxygen concentration in the air, it is possible to calculate oxygen flow $j$ through the boundary layer at a given surfactant concentration in the solution and other difusional parameters of the water surface layer [8].

Figure 2 shows the values of total oxygen diffusional flow $j$ at different surfactant concentrations compared with the total diffusional flow for pure water $j_{\max }$.

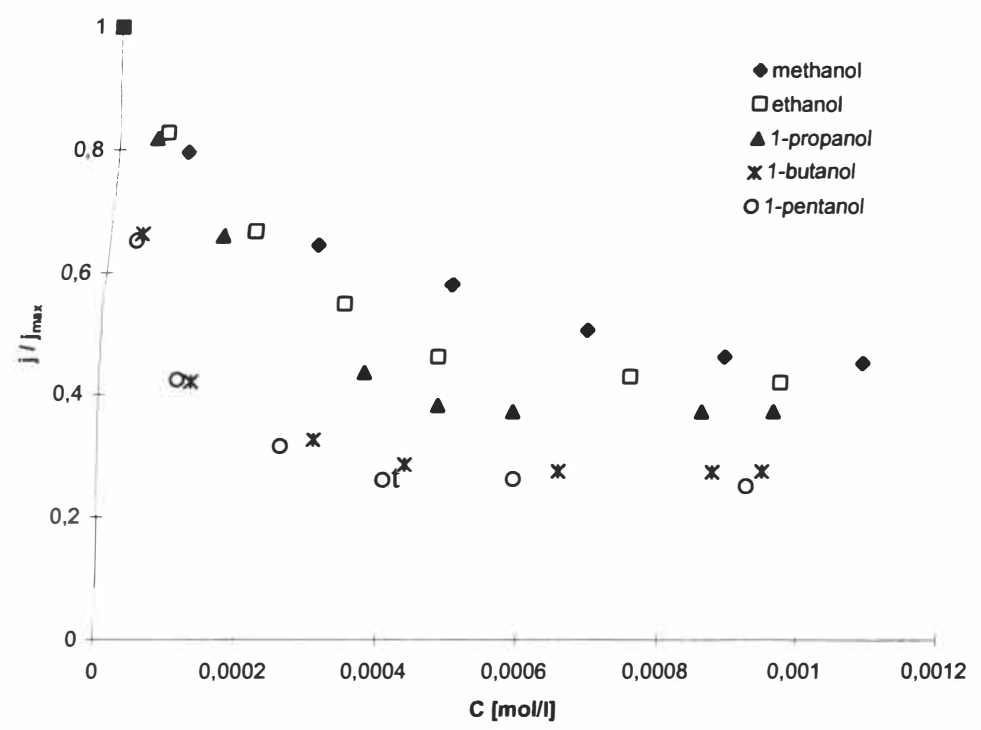

Figure 2. Relative value of the diffusional flow of oxygen depending on the surfactant concentration in the solution.

As seen from Figure 2, oxygen flow through the boundary layer decreases especially steeply at very low concentrations of surfactants. It can be explained with the adsorption of surfactants on the surface. If the concentration of surfactants increases, the relative 
KALMAR ECO-TECH'03

Bioremediation and Leachate Treatment

KALMAR, SWEDEN, November 25-27, 2003

increase of the surface area covered with surfactants decreases. An increase of the surfactant concentration causes a decrease of oxygen flow through the boundary layer. A further increase in the concentration of the surfactant in the solution finally results in the maximum surface concentration for this surfactant. In this case the value of oxygen flow approaches the value specific to the current surfactant. It is in accordance with the data from other authors, who have used different methods to determine oxygen mass-transfer through the air-water interface. The increase of the impediment of the boundary layer to oxygen mass-transfer as the number of carbon atoms in alcohols increases, is also clear (Figure 2) [9].

Table 1 gives values of the overall mass-transfer velocity of oxygen $\left(v_{t o t}\right)$ through selected wastewater surface layers, which is calculated by using technique described above. The overall mass-transfer velocity for the surface layer of the distilled water calculated by the technique is $14,2 \cdot 10^{-7}\left[\frac{\mathrm{m}}{\mathrm{s}}\right]$.

Table 1. Overall mass-transfer velocity of oxygen through selected wastewater surface layers.

\begin{tabular}{|l|c|}
\hline Pollution source & Overall transfer velocity [m/s] \\
\hline & \\
\hline Municipal & $2,23 \cdot 10^{-7} *$ \\
\hline Dairy & $2,38 \cdot 10^{-7} *$ \\
\hline Packing house & $3,34 \cdot 10^{-7} *$ \\
\hline Cardboard factory & $4,26 \cdot 10^{-7} *$ \\
\hline
\end{tabular}

* - - values are single results and are not characteristic for this category of wastewaters generally

\section{CONCLUSION}

- By using a special technique the mass-transfer rates of oxygen through the water-air interface were measured at different concentrations of water solutions of methanol, ethanol, 1-propanol, 1-butanol and 1-penthanol.

- Impact of surfactants to the diffusional property of air-water interface depends of surface concentration and structure of the surfactants.

- By means of the device developed by the author it is possible to measure the total impedance of the surface layer of water or solution to oxygen mass transfer.

- It makes possible to evaluate total costs of the wastewater treatment in biological treatment plant as main cost of the wastewater processing in step of biological treatment is energy consumed by aeration. 
KALMAR ECO-TECH'03

Bioremediation and Leachate Treatment

KALMAR, SWEDEN, November 25-27, 2003

\section{ACKNOWLEDGEMENTS}

This work was supported by the Institute of Physical Chemistry, the University of Tartu and by the Estonian Science Foundation Grant No. 3936.

\section{REFERENCES}

[1] Adamson, A.W., 1997: Physical Chemistry of Surfaces. Wiley-Interscience Publication, New York.

[2] Thibodeaux, L.J., 1966: Environmental Chemodynamics. Movement of Chemicals in Air, Water and Soil. $2^{\text {nd }}$ ed. Wiley-Interscience Publication, New York.

[3] Schwarzenbach, R.P., Gschwend, P.M., Imboden, D.M., 1993: Environmental Organic Chemistry. Wiley-Interscience Publication, New York.

[4] Aratono, M., Kanda, T., Motomura, K., 1990: Study on the Adsorption and Micelle Formation of a Decylsulfinylethanol and Octysulfinylethanol Mixture. Langmuir 6, 843846.

[5] Rosen, M.J., Hua, X.Y. 1982: Surface Concentrations and Molecular Interactions in Binary Mixtures of Surfactants. J Colloid Interface Sci 86 No 1, 164-172.

DOI: https://doi.org/10.1016/0021-9797[82)90052-2

[6] Lucassen-Reynders, E.H., Lucassen, J., Giles, D., 1981: Surface and Bulk Properties of Mixed Anionic/Cationic Surfactant System. J Colloid Interface Sci 81 Nol, 150-157. DOI: https://doi.org/10.1016/0021-9797[81)90312-X

[7] Mölder, E., Tenno, T., Nigu, P., 1998: The Influence of Surfactants on Oxygen MassTransfer through the Air-Water Surface. Crit Rev Anal Chem 28-2, 75-80.

[8] Mölder, E., Tenno, T., Mashirin, A., 2002: The effect of surfactants on oxygen mass-transfer trough the air-water interface. Environmental Science and Pollution Research Special Issue 1, 39-42. DOI: https://doi.org/10.1007/BF02987424

[9] Slevin, C.J., Ryley, S., Walton, D.J., Unwin, P.R., 1998: A New Approach for Measuring the Effect of a Monolayer on Molecular Transfer across an Air/Water Interface Using Scanning Electrochemical Microscopy. Langmuir Vol 14, 19, 53315334. 